\title{
Gelatinization Temperature of Starch in Dry Cell Electrolyte*
}

\author{
Takehiko TAKAHASHI ${ }^{* *}$
}

The gelatinization temperature of starch is known to be changed by the constitution of the electrolyte in which the starch is suspended. To offer the data for controlling the heating temperature to gelatinize starch, the gelatinization temperature of starch was measured in the dry cell electrolyte of various constitutions, and to draw a deduction on the cause of this change of the gelatinization temperature, the gelatinization temperatures in the various kinds of electrolytic solutions were measured.

The apparatus is shown in Fig. 1.

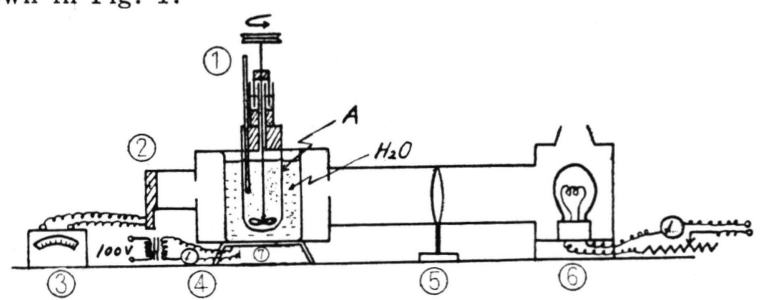

Fig. 1 Apparatus for measuring the gelatinization temperature of starch

To measure the gelatinization temperature, $100 \mathrm{cc}$ of the electrolyte in which $0.5 \mathrm{~g}$ starch is suspended is put in $\mathrm{A}$, and stirred by $300 \mathrm{rpm}$, and the temperature at $\mathrm{A}$ is raised by $1^{\circ}$ for every 5 minutes, and collimating the light irradiated from a 200 watt bulb, the focus is adjusted at the middle of A, and the intensity of light passed through $\mathrm{A}$ is measured by a photo cell. Thus the gelatinization temperature of starch was measured as the temperature at which the sudden change of the transparency of the solution in A was recognized. As the starch, wheat and potato starch, and as the electrolyte, the solutions of $\mathrm{NH}_{4} \mathrm{Cl}, \mathrm{ZnCl}_{2}$, the mixture of these salts, $\mathrm{NaCl}, \mathrm{KCl}, \mathrm{MgCl}_{2}, \mathrm{CaCl}_{2}, \mathrm{MgCl}_{2}$, $\mathrm{MnCl}_{2}, \mathrm{AlCl}_{3}, \mathrm{KNO}_{3}, \mathrm{Mg}\left(\mathrm{NO}_{3}\right)_{2}, \mathrm{Zn}\left(\mathrm{NO}_{3}\right)_{2}, \mathrm{NaBr}, \mathrm{KBr}, \mathrm{KI}, \mathrm{KCNS}, \mathrm{NaClO}_{3}, \mathrm{NaClO}_{4}, \mathrm{Na}_{2} \mathrm{SO}_{3}, \mathrm{Na}_{2} \mathrm{~S}_{2} \mathrm{O}_{3}$, $\mathrm{Na}_{2} \mathrm{HPO}_{4}$ and $\mathrm{ZnSO}_{4}$ were used.

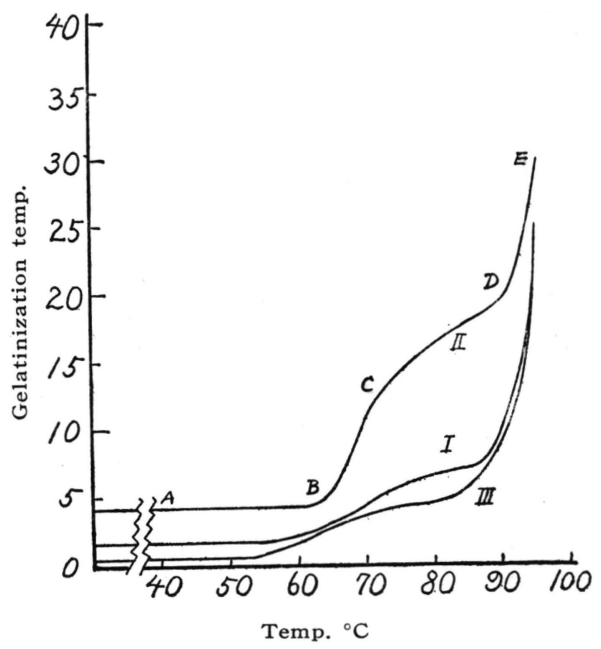

Fig. 2 Relation between the transparency of the solution and the temperature

* Studies on electrolytes for dry cells (part 11)

** Applied Chemistry, Faculty of Engineering, Nagoya University.

The original written in Japanese can be seen in J. Electrochem., Soc. Japan, 27, 233 (1959) 
The relation between the transparency of the solution and the temperature is illustrated in Fig. 2 .

In Fig. 2, I and II are the case of the wheat and potato starches in water, and III is the case of the wheat starch in $6.231 \mathrm{~mol} \mathrm{NH}_{4} \mathrm{Cl} / 1000 \mathrm{~g} \mathrm{H}_{2} \mathrm{O}$ solution. From Fig. 2, the gelatinization temperatures in water were determined as $57.0^{\circ}$ and $62.0^{\circ} \mathrm{C}$ for wheat and potato starches respectively, and these values were found to agree with those measured by Ohashi(1) from the sudden changes of the viscosities of the solution in which the starches were suspended.

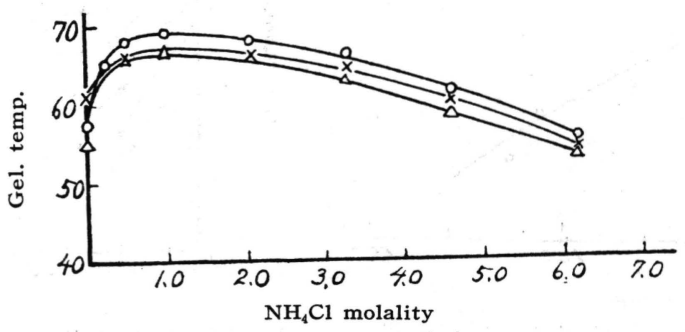

Fig. 3 Relation between the gelatinization temperature and the concentration of $\mathrm{NH}_{4} \mathrm{Cl}$

In Fig. 3, the gelatinization temperatures are plotted against the concentration of $\mathrm{NH}_{4} \mathrm{Cl}$. $\mathrm{As}$ clearly from Fig. 3, a maximum value of the gelatinization temperature was found to exist.

In Fig. 4, the relation between the gelatinization temperature and the concentration of $\mathrm{ZnCl}_{2}$ is shown. From Fig. 4, it was found that the tendency of the change of gelatinization temperature was analogus to the case of $\mathrm{NH}_{4} \mathrm{Cl}$ solution, but the lowering of the gelatinization temperature at high concentration was larger than the case of $\mathrm{NH}_{4} \mathrm{Cl}$ solution.

The gelatinization temperatures of the mixed solutions of $\mathrm{NH}_{4} \mathrm{Cl}$ and $\mathrm{ZnCl}_{2}$ are shown in Fig. 5, plotting them in one curve in which the molality of $\mathrm{ZnCl}_{2}$ is the same.

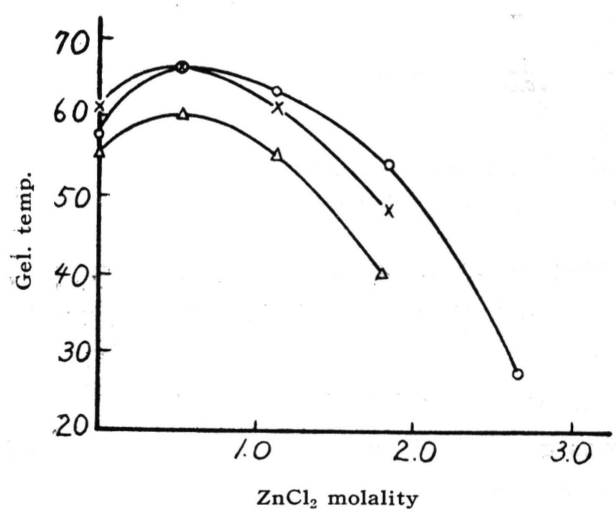

Fig. 4 Relation between the gelatinization temperature and the concentration of $\mathrm{ZnCl}_{2}$

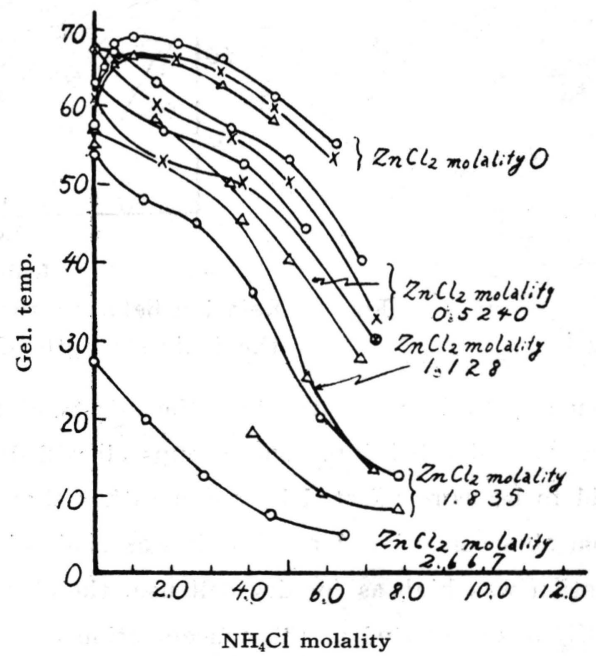

Fig. 5 The gelatinization temperature in the mixed solution of $\mathrm{NH}_{4} \mathrm{Cl}$ and $\mathrm{ZnCl}_{2}$

Fig. 5 showed that the gelatinization temperature became lower as the concentration of $\mathrm{NH}_{4} \mathrm{Cl}$ got higher and when these gelatinization temperatures were plotted against the ionic strengths in solutions, one curve was obtained as Fig. 6 .

From Fig. 6, it could be presumed that the effect of the electrolyte on the gelatinization of starch would be considered to be ionic. 
Further, the gelatinization temperatures are plotted versus the concentration of the various kinds. of electrolytes in Fig. 7.

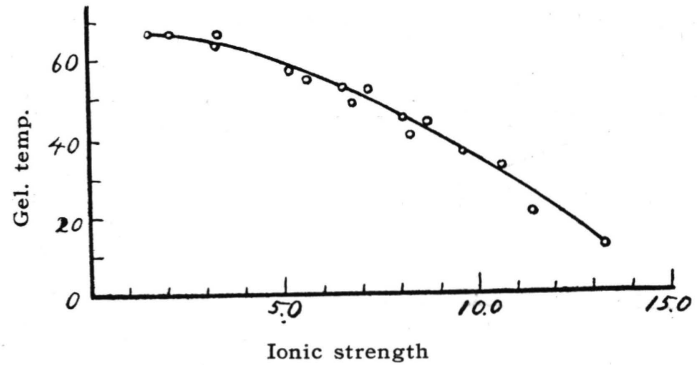

Fig. 6 Relation between the gelatinization temperature and the ionic strength of the mixed solution of $\mathrm{NH}_{4} \mathrm{Cl}$ and $\mathrm{ZnCl}_{2}$

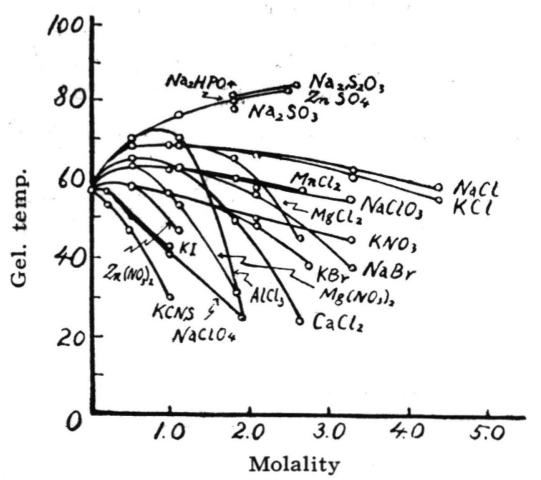

Fig. 7 The gelatinization temperature in the solution of the various kinds of electrolytes

From Fig. 7, when the magnitudes of the effects of the electrolytes upon gelatinization temperature were compared with each other, a series analogous to the lyotropic series was obtained with cations as well as anions. If these gelatinization temperatures are plotted against the ionic strengths of the electrolytes, Fig. 8 will be obtained.

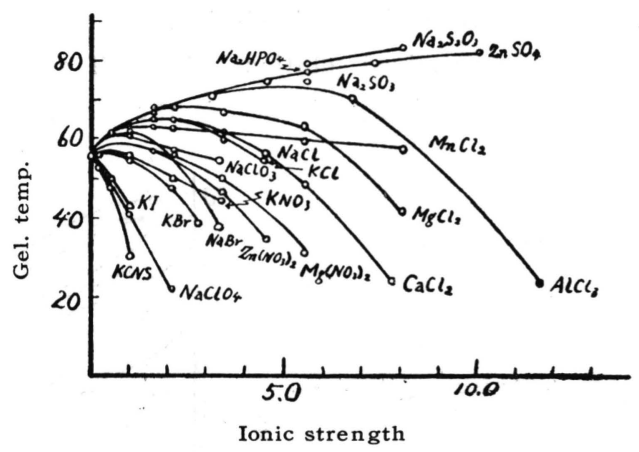

Fig. 8 Relation between the gelatinization temperature and the ionic strength of the various kinds of electrolyte

From Fig. 8, it was found that the effects of the electrolytes on the gelatinization temperature of starch were divided into some groups classified by the anions, that is, the gelatinization temperature is said to be more affected by anion rather than cation.

From above mentioned results, it was made clear that in the electrolyte in which the $\mathrm{NH}_{4} \mathrm{Cl} \mathrm{con}_{-}$ centration was high as for dry cell use, the electrolyte was gelatinized by starch at room temperature if $\mathrm{ZnCl}_{2}$ was coexisted at the concentration of above $2 \mathrm{~mol} / 1000 \mathrm{~g} \mathrm{H}_{2} \mathrm{O}$.

(Received 19 th, February 1959)

\section{Literature :}

(1) K. Ohashi : Research Bull. Faculty Agr. Gifu Univ. 5, 63 (1955) 